\title{
Demonstration of Succinic Dehydrogenase in the Mesosomes of the Mycelial Phase of Paracoccidioides brasiliensis
}

\author{
By SYLVIA LEIVA AND L. M. CARBONELL \\ Centre for Microbiology, Instituto Venezolano de Investigaciones Cientificas, \\ Apartado 1827 , Caracas, Venezuela
}

(Accepted for publication Io March 1970)

SUMMARY

In the hypha of Paracoccidioides brasiliensis the succinic dehydrogenase activity is localized in the mesosomes, plasma membrane and mitochondria. Short permanganate fixation after incubation enhances the positive cytochemical reaction. The higher activity is localized in mesosomes and it is observed as high electron-dense zones and concentric ring-like patterns. The membrane shows a spotty reaction and the mitochondrion shows a positive zone in the intracristae space.

\section{INTRODUCTION}

Mesosomes or intracytoplasmic membrane systems have been demonstrated in several fungi (Edwards \& Edwards, I960; Moore \& McAlear, I96I; Carbonell \& Rodriguez, I968). Light microscope demonstrations of reductases have been done in Saccharomyces cerevisiae (Reiss, I967a), Neurospora crassa (Reiss, I967b, 1968) and Paracoccidioides brasiliensis (Carbonell \& Kanetsuna, 1966). Different types of oxido-reductase have been demonstrated cytochemically and biochemically in the mesosomes of Gram-positive bacteria (Vanderwinkel \& Murray, I962; van Iterson \& Leene, I964; Sedar \& Burde, 1965; Ferrandez, Chaix \& Ryter, I966; Cesari, Rieber \& Imaeda, I969; Reaveley \& Rogers, 1969). Morphologically, the mesosomes of fungi and bacteria are very much alike and the similarities could be confirmed if they were shown to have similar cytochemical characteristics. The purpose of the present work is to demonstrate succinic dehydrogenase activity in the mesosomes of Paracoccidioides brasiliensis.

\section{METHODS}

The mycelial phase of Paracoccidioides brasiliensis (IVIC-Pb9) was inoculated into a GGY medium (glycine I \%, glucose $2 \%$, yeast extract $0.2 \%$ ) in Erlenmeyer flasks which were placed on a reciprocal shaker at 100 oscillations/min., stroke amplitude $5 \mathrm{~cm}$., at 20 to $22^{\circ}$.

Four-day-old samples were harvested by low speed centrifugation and incubated for 30 to $50 \mathrm{~min}$. in the following mixture: $3.5 \mathrm{ml} .0 .8 \mathrm{M}$-sodium succinate, tetranitro blue tetrazolium (TNBT) I mg./ml., which had been previously dissolved in $N, N$ dimethylformamide (Sedar, Rosa \& Tsou, 1962; Sedar \& Burde, I965). For controls, sodium malonate $(0.5 \mathrm{~g}$.) was added to the incubated mixture as a competitive inhibitor; the material was incubated without substrate; and the enzyme was inactivated 
with glutaraldehyde, or by treating at $65^{\circ}$ to $80^{\circ}$ for $10 \mathrm{~min}$. The material was then fixed.

As previously shown (Carbonell \& Kanetsuna, I966), the intrinsic factors which reduced the tetrazolium salt are eliminated by treating the samples with cold acetone for $10 \mathrm{~min}$. before incubation, and washing in a mixture of $0.2 \mathrm{M}$-phosphate buffer $(\mathrm{pH} 7 \cdot 4$ ) and Ringer solution $(\mathrm{I}: 9, \mathrm{v} / \mathrm{v})$. Following incubation, the samples were harvested by low speed centrifugation. Acetate-veronal buffer of Michaelis, $\mathrm{pH}$ 6. I (Kellenberg, Ryter \& Séchaud, 1958), was used for preparing the fixative, for washing and for the agar solution.

After incubation, different fixation procedures were used: $(a)$ I $\%$ osmium tetroxide at 20 to $22^{\circ}$ for $12 \mathrm{~h}$; ; (b) $5 \%$ glutaraldehyde at $4{ }^{\circ}$ for $\mathrm{I} 2 \mathrm{~h}$.; (c) fixation as in $(b)$, and postfixed as in $(a)$, for $3 \mathrm{~h}$.; and $(d)$ permanganate fixation for 10 min. or less at $4{ }^{\circ}$ following the technique of Kellenberg et al. (1958). To facilitate manipulation, the fixed material was embedded in $2 \%$ agar. It was then dehydrated with ethanol and embedded in Maraglas (Freeman \& Spurlock, 1962). Sections were cut with diamond knives and examined with a Hitachi II B electron microscope. For morphological details, samples were also fixed in glutaraldehyde and postfixed in osmium tetroxide, embedded in Maraglas and stained with lead nitrate and uranyl acetate.

\section{RESULTS}

The fine structure of the untreated mycelia of Paracoccidioides brasiliensis has been reported (Carbonell \& Rodriguez, I968). The following brief description will deal only with the features relevant to the present topic. The structure of the plasma membrane varied according to the sectioning angle. When attached to the cell wall it appeared as a wide electron-dense layer, or as a three-layered structure (an outer wide electron-dense layer, a low-density middle space and a very narrow inner electrondense layer). The invaginations of the plasma membrane are interpreted as the beginning of mesosomes. This membranous system, formed by the apposition of the infolded plasma membrane, underwent additional invaginations, forming multivesicular or lamellar structures that are interpreted as tubular infoldings of the plasma membrane seen in different sectioning angles (Pl. I, fig. I; Pl. 3, fig. 7; Pl. 4, fig. II). In addition to the plasmalemma and mesosomes, a cell wall with septum, septal bodies (Woronin bodies), nuclei, mitochondria, glycogen and vacuoles was identified (Pl. I, fig. I; Pl. 3, fig. 6, 7).

In media containing succinate, TBNT and buffer, TBNT showed reduction within a few minutes. When malonate was present and when enzymes were inactivated, the reduction of the TBNT was minimal.

The best fixation procedures used were glutaraldehyde + osmium and $\mathrm{KMnO}_{4}$ fixations. Fixation with glutaraldehyde before incubation almost completely destroyed the enzymic activity (Seligman et al. 1967) and there was no increase in morphological details.

Deposits of TBNT-formazan (TNF) were found in the plasma membrane (Pl. I, fig. 2; Pl. 2, fig. 5; Pl. 3, fig. 6) and mesosomes (Pl. I, fig. 2, 3; Pl. 2, fig. 4; Pl. 3, fig. 8). In the plasma membrane they appeared scattered as electron-dense lines. The positive reaction of the plasma membrane was present near the mesosomes and in the membrane that embraced it (Pl. I, fig. 2 ; Pl. 2, fig. 5). In the mesosomes, TNF appeared 
as a homogeneous confluent electron-dense deposit (Pl. 2, fig. 4; Pl. 4, fig. II) or as a concentric ring-like pattern (Pl. 2, fig. 4 ; Pl. 3, fig. 8). In some mesosomes one or other of the two patterns predominated. When the concentric ring-like pattern appeared it seemed that the reaction was not completely positive in the whole structure (PI. I, fig. 2 ; Pl. 2, fig. 4). Some mesosome structures showed heterogeneity in their reaction, as demonstrated by a clear positive zone near to a completely negative area (Pl. 4, fig. II). In rare instances a deposit of needle-like microcrystals lying outside the cell wall was seen. Their significance cannot yet be explained. The reaction of the mitochondria in the material studied was localized in the intracristae space and in the outer membrane (Pl. 4, fig. I2). The small number of cristae in the mitochondria is noteworthy.

With malonate and the incubation mixture without substrate, or with inactivation of the enzyme with heat or fixation, some electron-density persisted in the mesosome (Pl. 4, fig. 9, IO).

\section{DISCUSSION}

The results show that the succinic dehydrogenase (SDH) activity of Paracoccidioides brasiliensis was mainly found in the mesosomes and less in the plasma membrane and mitochondria. The fine structure and the localization of the positively reacting zones near the septum and the cell wall identify these as mesosomes (Carbonell \& Rodriguez, 1968). The positive reaction observed in the mesosome of a hypha of $P$. brasiliensis was due to SDH activity, since it appeared only when the incubation mixture had succinate as substrate and was not observed when the enzyme was inactivated or inhibited, or when the incubation mixture was used without substrate, as shown in Pl. 4, fig. 9, I0. Incubation with succinate followed by shorter permanganate fixation than the one commonly used (Kellenberg et al. 1958; Mollenhauer, I959) proved to be the best procedure to demonstrate SDH activity. It was better than glutaraldehyde+ osmium fixation because the electron-dense zones were more clearly delimited and the electron density was higher.

We presume that the high electron density is due to three factors: the electron density given by the TNF (Seligman et al. 1967), by the potassium permanganate when used alone (Bradbury \& Mek, I960; Hopwood, 1969) and by the oxidation of formazan by potassium permanganate. The most important factor is the enhancement of the reaction when permanganate is used. Due to the fact that mesosomes are made by complex infoldings of the plasma membrane, and the SDH is associated with the infoldings, the electron densities vary with the concentration of SDH in a given area.

The heterogeneity of mitochondria with respect to SDH activity has been shown by Seligman et al. (1967) and Ogawa \& Barnett (1964). The first authors saw an allor-none reactivity of the mitochondrion, while Ogawa \& Barnett (1964) observed heterogeneity of the reaction inside the same mitochondrion. Dense zones and ne. ative areas were seen in our material, indicating heterogeneity of reaction.

It is interesting to note that the hypha of Paracoccicioides brasiliensis has mitochondria and mesosomes (Carbonell \& Rodriguez, 1968) and that SDH activity is found in both membranous systems, but much more in the mesosomes than in the mitochondria. Carbonell \& Rodriguez (1968) demonstrated a close ultrastructural relationship between the mesosome and the formation of the septum which is part of the cell 
wall. Since SDH activity was found in mesosomes, it is possible that respiratory activity present in the mesosome has something to do with the building of the cell wall.

\section{REFERENCES}

BRADBURY, S. \& MeK, G. (I690). A study of potassium permanganate fixation for electron microscopy. Quarterly Journal of Microscopical Science ror, $24 \mathrm{I}$.

CarbonelL, L. M. \& KaNETSUNA, F. (1966). Nature of the intrinsic factors which reduced tetrazolium salt in the histochemical demonstration of dehydrogenases in the fungus Paracoccidioides brasiliensis. Annales d'Histochimie II, 375.

Carbonell, L. M. \& Rodriguez, J. (I968). Mycelial phase of Paracoccidioides brasiliensis and Blastomyces dermatitidis: an electron microscope study. Journal of Bacteriology 96, 533.

Cesari, I. M., Rieber, M. \& IMAEDA, T. (1969). Localization and properties of enzymes involved with electron transport activity in mycobacteria. Journal of Bacteriology 98, 767.

EDWARDS, G. A. \& EDWARDS, M. R. (1960). The intracellular membrane of Blastomyces dermatitidis. American Journal of Botany 47, 622.

Ferrandez, B., Chaix, P. \& Ryter, A. (1966). Localization des cytochromes de Bacillus subtilis dans les structures mesosomique. Compte Rendu Hebdomadaire des Séances de l'Academie des Sciences, Paris 63, 1632 .

Freeman, J. M. \& Spurlock, B. O. (1962). A new epoxy embedment for electron microscopy. Journal of Cell Biology 13, 437.

Hopwoon, D. (1969). Fixatives and fixation: a review. Histochemistry I, 323.

KellenberG, E., RYTer, A. \& SÉchAUd, J. (1958). Electron microscope study of DNA-containing plasms. II. Vegetative and mature phage DNA as compared with normal bacterial nucleoids in different physiological states. Journal of Biophysical and Biochemical Cytology 4, 67I.

Mollenhauer, H. H. (1959). Permanganate fixation of plant cells. Journal of Biophysical and Biochemical Cytology 4, 67I.

MOORE, R. T. \& MCALEAR, J. (I96I). Fine structure of mycota 5. Lomasomes, previously uncharacterized hyphal structures. Micologia $\mathbf{5 3}, 194$.

OgaWA, K. \& BarnetT, R. J. (1964). Electron histochemical examination of oxidative enzymes and mitochondria. Nature, London $203,724$.

Reaveley, D. A. \& Rogers, H. S. (1969). Some enzymatic activities and chemical properties of the mesosomes and cytoplasmic membranes of Bacillus licheniformis 6346. Biochemical Journal Ir3, 67.

ReIss, J. (1967a). Cytochemical demonstration of glutathione reductase in Saccharomyces cerevisiae. Journal of Histochemistry and Cytochemistry 15, 273.

Reiss, J. (1967b). Der cytochemische Nachweis von Cytochromoxydase und Peroxydasen bei Pilzen. Histochemie 9, 28I.

Reiss, J. (1968). Grundsätzliches zum cytochemischen Nachweis von Dehydrogenasen bei Pilzen. Zentralblatt für Bakteriologie Parasitenkunde, Infektionskrankheiten und Hygiene 207, 231.

SEDAR, A. W. \& BuRdE, R. M. (1965). The demonstration of the succinic dehydrogenase system in Bacillus subtilis using tetranitro-blue tetrazolium combined with techniques of electron microscopy. Journal of Cell Biology 27, 53.

Sedar, A. W., Rosa, C. \& Tsou, K. (1962). Tetranitro-blue tetrazolium and the electron histochemistry of succinic dehydrogenase. Journal of Histochemistry and Cytochemistry 10, 506.

Seligman, A. M., Ueno, H., Morizono, Y., Wasserkrug, H., Katzoff, L. \& Hanker, J. (I967). Electron microscopic demonstration of dehydrogenase activity with a new osmiophilic ditetrazolium salt (TC-NBT). Journal of Histochemistry and Cytochemistry 15, I.

V . NDERWINKEL, E. \& MURRAY, R. G. E. (1962). Organelles intracytoplasmiques bactériens et site d'activité oxydo-reductrice. Journal of Ultrastructure Research 7, 195.

VAN IteRson, W. \& LeENE, W. (1964). A cytochemical localization of reductive sites in a Grampositive bacterium. Tellurite reduction in Bacillus subtilis. Journal of Cell Biology 20, 36r. 
Journal of General Microbiolog.', Vol. 62, No. I

Plate I
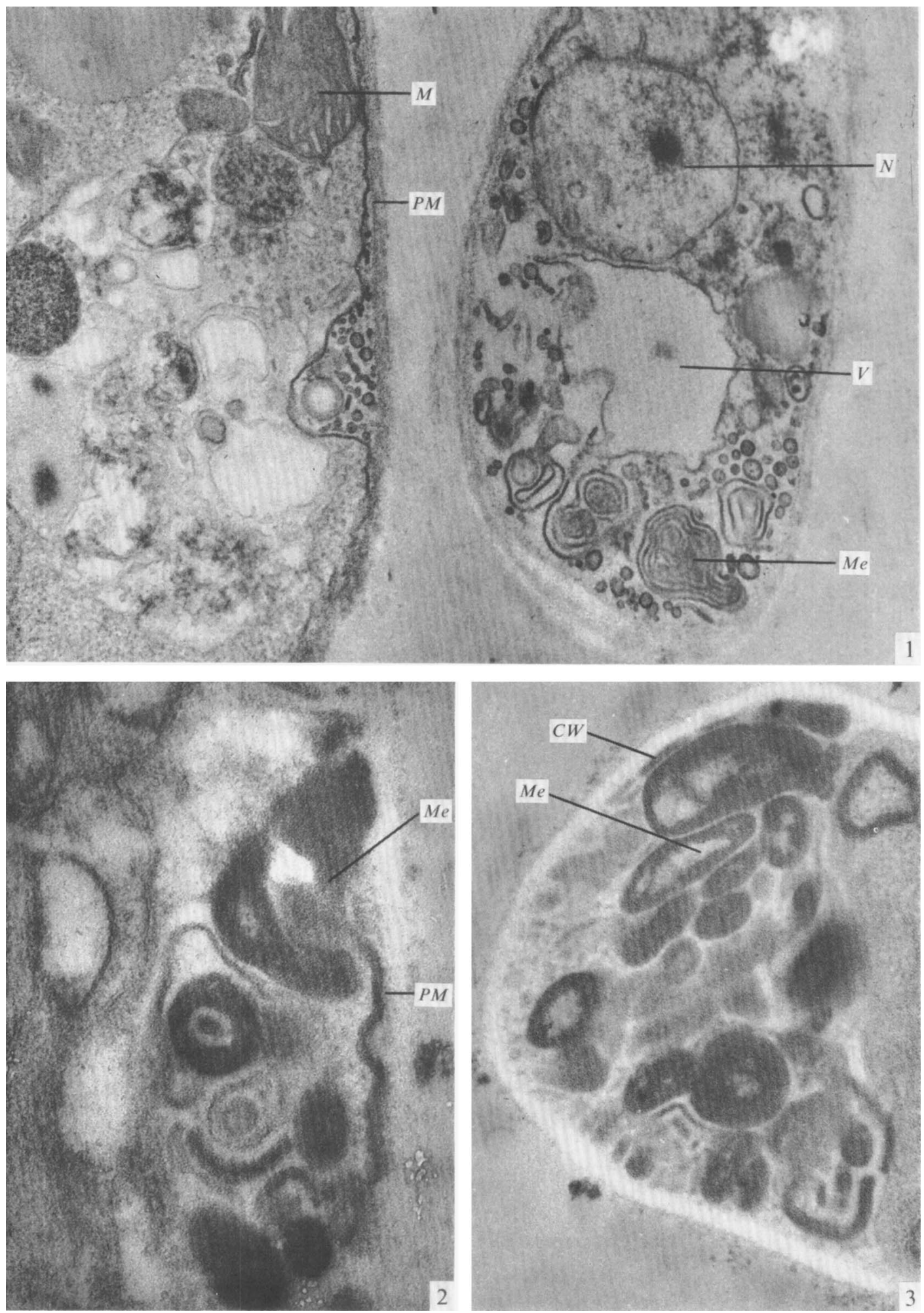

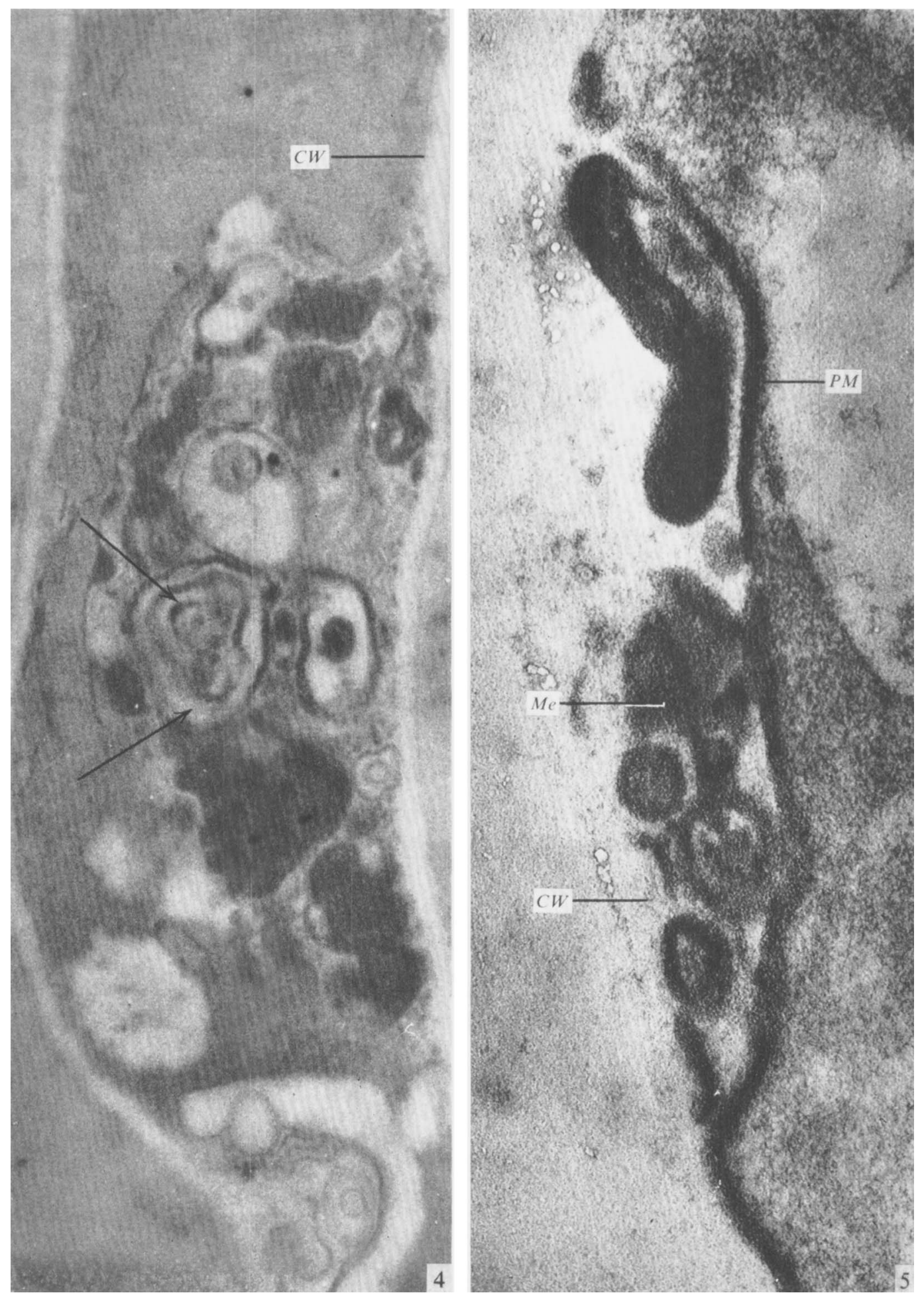

S. LFIVA ANI) I. M. CARBONELLL 

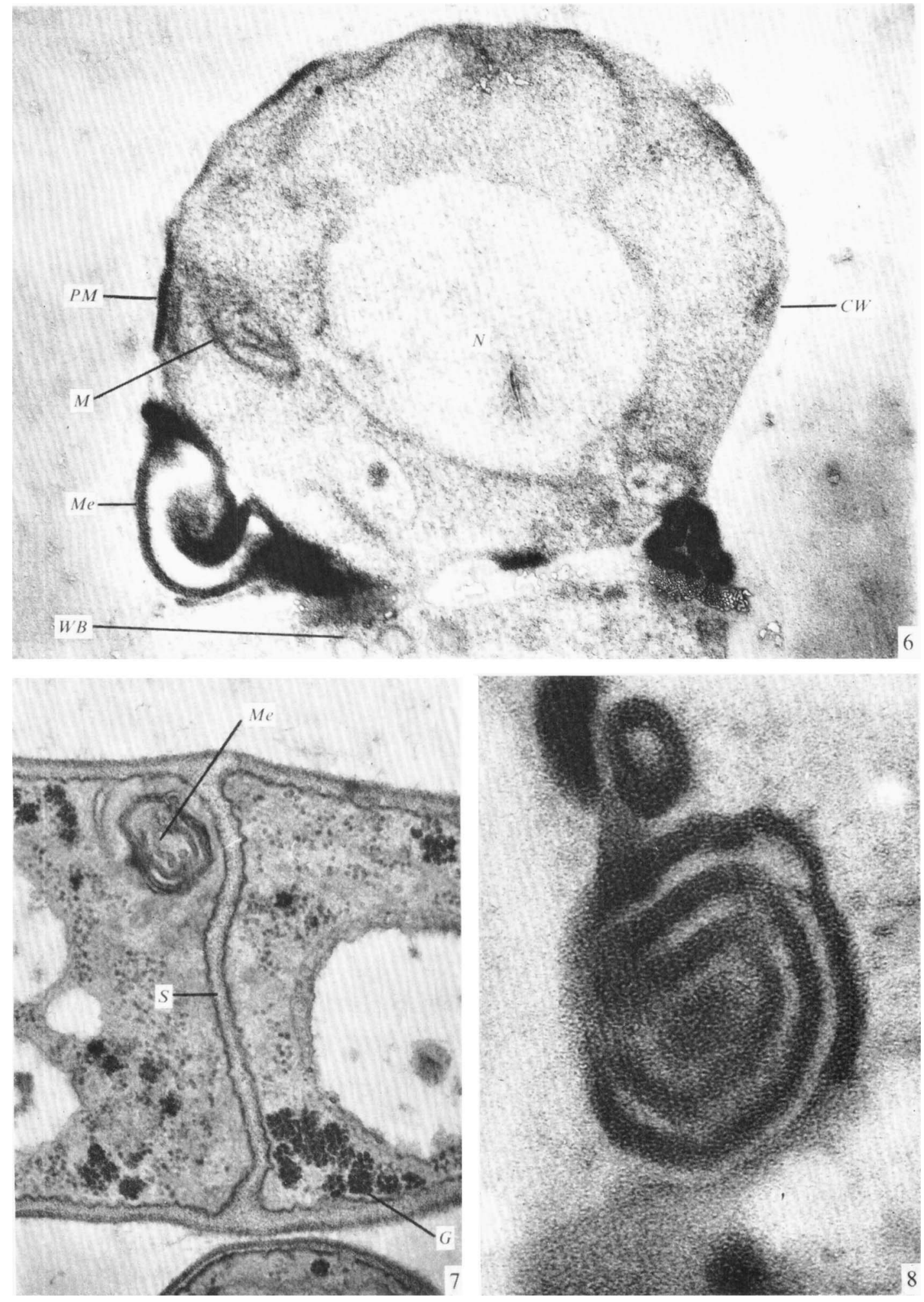

S. I.EIVA NNDI. M. CARBONFII 
Journal of General Microbiology, Vol. 62, No. I

Plate 4
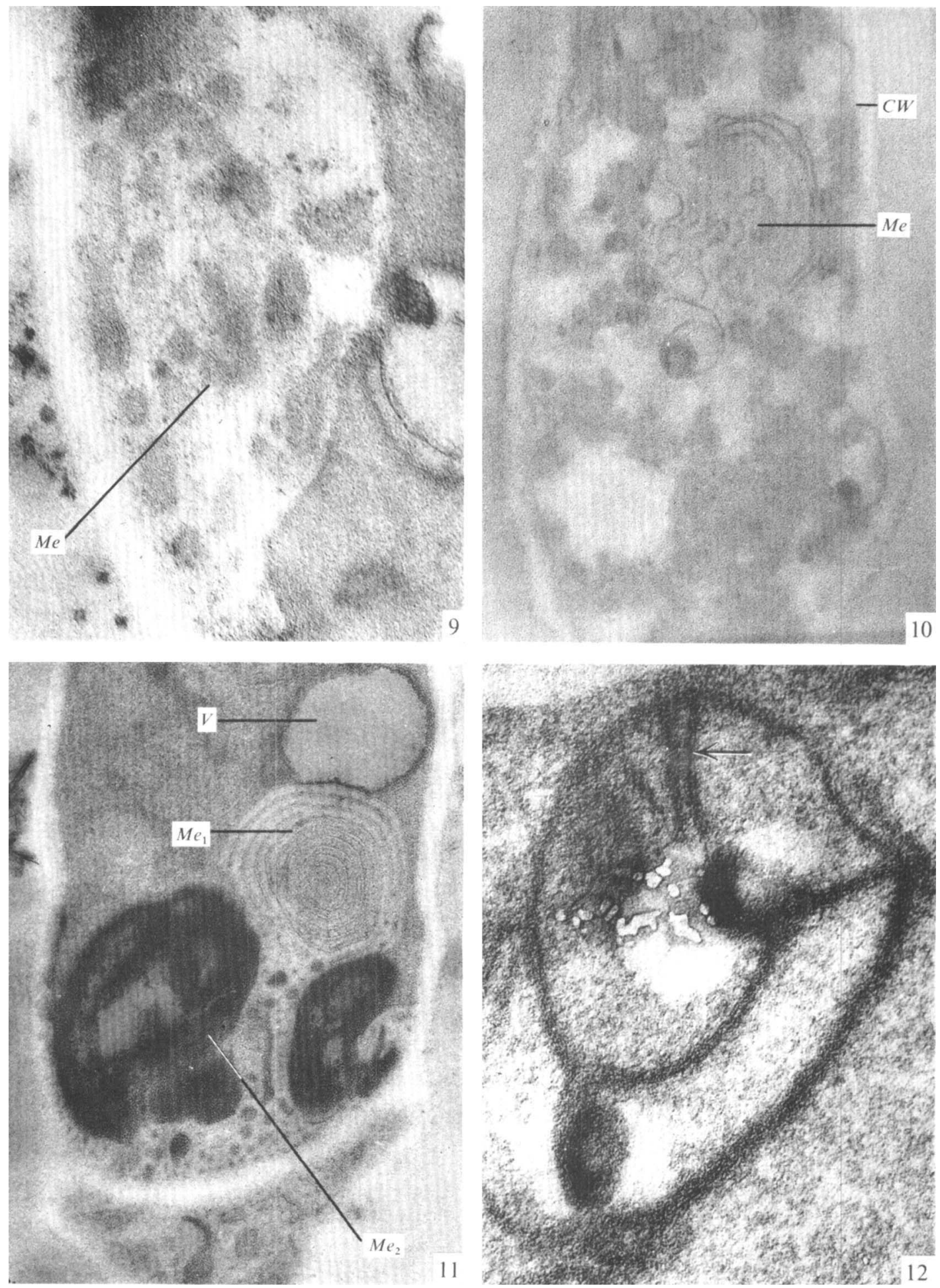

S. LEIVA ANI I. M. CARBONFILI. 


\section{EXPLANATION OF PLATES}

In the following figures, $G$ signifies glycogen; $N$, nucleus; $M$, mitochondria; $V$, vacuole; $P M$, plasma membrane; $C W$, cell wall; $M e$, mesosomes; $S$, septum; $W B$, Woronin bodies.

\section{Plate I}

Fig. I. Mycelial phase of Paracoccidioides brasiliensis. Observe the nucleus, mitochondria, vacuoles plasma membrane, cell wall and mesosomes which are formed by a whorl of membranes and tubulovesicular structures. Glutaraldehyde + osmium tetroxide fixation with lead nitrate + uranyl acetate stain. $\times 24,000$.

Fig. 2. Observe deposits of TNF indicating succinic dehydrogenase activity in the mesosome and a portion of plasma membrane. Incubation mixture, $\mathrm{KMnO}_{4}$ fixation without stain. $\times 76,000$.

Fig. 3. Mesosomes at the tip of a hypha. Observe the heterogeneous reactivity of the mesosome, the electron-dense zones in contrast with others of less electron density. Note the low electron density of the cell wall. Incubation mixture, $\mathrm{KMnO}_{4}$ fixation without stain. $\times 68,000$.

\section{Plate 2}

Fig. 4. A large mesosome with many positively and negatively reacting areas. Note (arrows) that in some of the concentric ring-like structures the membrane has different electron densities. Incubation mixture, glutaraldehyde + osmium fixation, without stain. $\times 40,000$.

Fig. 5. This shows a well-defined and positive reaction at the mesosome, and at the plasma membrane which delimited it. The cell wall is completely negative. Incubation mixture, $\mathrm{KMnO}_{4}$ fixation without stain. $\times 100,000$.

$$
\text { Plate } 3
$$

Fig. 6. Septal mesosomes. Portions of the plasma membrane show an electron density similar to that observed in the mesosomes. Nucleus, mitochondria and three Woronin bodies are also seen. Incubation mixture, $\mathrm{KMnO}_{4}$ fixation without stain. $\times 60,000$.

Fig. 7. Septal mesosome in which a clcarly delimited membrane is seen. Glutaraldehyde + osmium fixation with stain. $\times 45,000$.

Fig. 8. In this mesosome note high electron density of each whorl. Incubation mixture, $\mathrm{KMnO}_{4}$ fixation without stain. $\times 144,000$.

$$
\text { PLATE } 4
$$

Fig. 9. Observe the very low electron density in the mesosome. Incubation mixture without substrate; $\mathrm{KMnO}_{4}$ fixation without stain. $\times 90,000$.

Fig. 10. Observe a very low electron density in the mesosome. Incubation mixture without substrate. Glutaraldehyde + osmium fixation without stain. $\times 60,000$.

Fig. I I. Heterogeneity of the reaction in the mesosome structure. Compare well delimited structure with negative reaction $\left(M e_{1}\right)$ with other $\left(M e_{2}\right)$ which shows a positive reaction. Incubation mixture, $\mathrm{KMnO}_{4}$ fixation without stain. $\times 70,000$.

Fig. I2. A mitochondrion with positive reaction located in the outer membrane and in the intracristae space. Incubation mixture, $\mathrm{KMnO}_{4}$ fixation without stain. $\times 80,000$. 